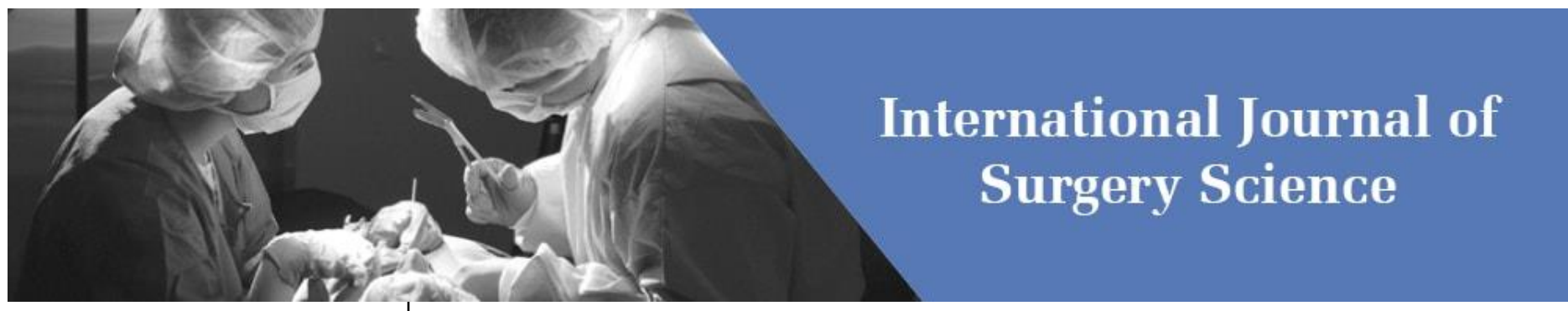

E-ISSN: 2616-3470

P-ISSN: 2616-3462

(C) Surgery Science

www.surgeryscience.com

2020; 4(2): 632-635

Received: 22-02-2020

Accepted: 24-03-2020

Dr. Ketan Vagholkar

Professor, Department of surgery

D.Y.Patil University School of

Medicine Navi Mumbai,

Maharashtra, India
Corresponding Author: Dr. Ketan Vagholkar Professor, Department of surgery D.Y.Patil University School of

Medicine Navi Mumbai,

Maharashtra, India

\section{Gallstone ileus}

\section{Dr. Ketan Vagholkar}

DOI: https://doi.org/10.33545/surgery.2020.v4.i2g.457

\section{Abstract}

Gall stone ileus is complication of cholithiasis. It is rare and seen in aged patients diagnosed as cholelithiasis with co morbidities. High index of suspicion is necessary for arriving at a clinical diagnosis. Contrast enhanced computed tomography is diagnostic. Enterolithotomy followed by closure of the fistula with cholecystectomy as a two staged procedure is the safest approach for managing gall stone ileus.

Keywords: Gall stone ileus diagnosis management

\section{Introduction}

Gallstone ileus is a complication of cholelithiasis $[1,2,3]$. It is usually seen in the elderly population. The actual pathology is frank bowel obstruction. Therefore the word ileus is a misnomer. Persistence of inflammation and pressure changes leads to formation of an internal biliary enteric fistula. As a result the gall stone reaches the lumen of the bowel wherein it gets impacted causing obstruction at the site of narrowing. The commonest site is the terminal ileum $[3,4]$. The pathophysiology, clinical features and management are discussed in this paper.

\section{Aetiopathology}

Gall stone ileus will occur if the gallstone enters the lumen of the intestine. This follows the formation of a biliary enteric fistula. Biliodigestive fistula is a rare complication of cholelithiasis occurring in less than $1 \%$ of patients with gallstones ${ }^{[5,6,7]}$.

Chronic cholecystitis leads to persistent inflammation of the gall bladder and the surrounding tissues especially the adjacent gastrointestinal tract. This leads to adhesion formation. Persistent pressure of the gallstone leads to thinning of the gall bladder wall. Pressure necrosis causes erosion of the thinned out gall bladder wall. An internal fistula is formed between the gall bladder and the adjacent gut ${ }^{[8,9,10]}$. The part of the gut involved in the fistula usually is the duodenum followed by other parts including the colon. The gallstone then passes freely down the gut until it gets impacted at the site of narrowing which in majority of cases happens to be at the ileocecal junction ${ }^{[11,12,13]}$.

The other pathway for the gallstone to reach the gut is into the common bile duct and then into the duodenum through a dilated ampulla of Vater. The process might be a part of the natural history of Mirizzi's syndrome ${ }^{[14,15,16]}$.

The other causes for gallstone ileus could be after ERCP wherein a wide sphincterotomy can cause a gall stone to find its way into the duodenum and pass down ${ }^{[17,18]}$.

Spillage of stones during laparoscopic cholecystectomy can lead to intra-abdominal abscesses which can ulcerate into the intestinal wall releasing the stone into the intestine leading to gall stone ileus ${ }^{[19,20]}$

The commonest biliodigestive fistula is cholecystoduodenal followed by cholecystocolic, cholecystogastric and choledochoduodenal fistula.

The predisposing factors are long standing history of cholelithiasis, repeated attacks of cholangitis, large size of the calculus(usually exceeding $2.5 \mathrm{~cm}$ ) and advanced age (>60 years) $[21,22,23]$.

The passage of the large gallstone through the fistula can manifest in a variety of forms depending upon a few variables. ${ }^{[24,25]}$ These include

1. Size of the gallstone

2. The part of the alimentary tract involved in the fistula and

3. The pre-existence of stenotic areas at the level of obstruction. 
The gall stone then exhibits tumbling advancement phenomenon and progresses forward till it gets impacted. The sites of impaction are ileum (50-60\%), jejunum (16-26\%), duodenum $(3.5-14.6 \%)$ and colon $(3-4 \%))^{[26,27,28]}$.

Bouveret syndrome is a condition where the gallstone gets impacted in the duodenal bulb leading to gastric outlet obstruction [13]. The associated fistula could either be cholecystoduodenal or choledochoduodenal in nature. Other rare sites of impaction are at the site of narrowed anastomosis in a partial gastrectomy with Billroth II reconstruction and at the site of a biliary enteric anastomosis ${ }^{[12,13]}$. Presence of diverticula, neoplasms, or intestinal strictures secondary to Crohn's disease cause decrease in the luminal diameter thereby predisposing to impaction. In the colon the site of impaction is the sigmoid colon. Once impacted the clinical features of intestinal obstruction usually become manifest leading to gross dehydration accompanied with fluid and electrolyte depletion especially in the aged population. Once obstruction is relieved by removing the stone by enterolithotomy the cholecystointestinal fistula may have a variable course if not dealt with at the first operative intervention. If the cystic duct is patent then there is a high likelihood of spontaneous closure of the fistula. There is no fixed timing as to when this can happen. However if the cystic duct is not patent then the fistula will retain its patency leading to recurrent complications ${ }^{[29]}$. The effects of a persistent biliary-enteric fistula are

1. Recurrent gallstone ileus

2. Cholangitis (11\% of cholecystoduodenal fistulas and $60 \%$ of cholecystocolonic fistulas)

3. Retrograde cholecystitis

4. Gall bladder cancer in $15 \%$ of cases.

\section{Clinical features}

In $85 \%$ of cases the gall stone is eliminated either by vomiting or passed in the faeces ${ }^{[30]}$. $15 \%$ of patients will present as gall stone ileus due to impaction in the digestive tract ${ }^{[17,18]}$. Nausea, anorexia and abdominal pain are the typical features. Pain is colicky and intermittent in nature located in the epigastrium and the right hypochondrium. Vomiting is a common accompanying symptom. Vomitus will initially contain gastric contents. Later on the contents become darker in colour and feculent. This is due to "tumbling" gallstone advancement. There will be intermittent periods of remission. Once the stone gets impacted there will be features of complete obstruction. In Bouveret's syndrome there will be features of gastric outlet obstruction. Nausea, vomiting of gastric contents and colicky abdominal pain in the epigastrium relieved by vomiting. Weight loss, anorexia, early satiety and constipation are other symptoms. Occasionally hematemesis and malaena will also be seen. The stone may in a few cases migrate proximally into the stomach and possibly be vomited out.

Physical examination will reveal dehydration, fever, tachycardia and jaundice in a few cases. Per abdominal examination will reveal abdominal distension, tenderness and features suggestive of peritonitis in advanced cases. In a few cases there may not be any features suggestive of obstruction at the time of presentation.

The main cause of delay in seeking medical attention is tumbling phenomenon. Patients usually present 4-8 days after the beginning of symptoms and the diagnosis is further delayed.

History of prior biliary symptoms are seen in $27-80 \%$ of patients $[10,11]$. Acute cholecystitis is seen in only $1-20 \%$ of cases at the time of bowel obstruction. Jaundice may be seen in $15 \%$ of cases ${ }^{[10]}$. Biliary symptoms may be absent in one third of cases.
Co morbidities are very common in these patients as these patients are quite old usually over 70 years of age ${ }^{[19]}$.

\section{Investigations}

Raised leukocyte count is seen. The severity of alteration in the fluid and electrolyte balance will depend upon the duration of obstructed state. Serum amylase level will be raised. Some patients may exhibit features suggestive of renal failure. In patients presenting with jaundice there will raised total and direct bilirubin in addition to raised alkaline phosphatase and gamma glutamyl trans peptidase ${ }^{[31]}$.

Abdominal x ray (AXR) will show Rigler's triad of signs in 25$30 \%$ of cases ${ }^{[22,29,30]}$.

1. Pneumobilia

2. Small bowel obstruction

3. Ectopic gall stone

Change of position of the stone on serial films is an additional radiological feature. A fifth sign is the presence two air fluid levels in the right upper quadrant on AXR ${ }^{[31]}$. The medial level corresponds to the duodenum and the lateral level corresponds to the gall bladder. These features may be found in $24 \%$ of presentations ${ }^{[32,33]}$.

\section{In Bouveret's syndrome AXR will reveal}

1. Dilated stomach

2. Calcified right upper quadrant mass (gall stone)

3. Gastric distension

4. Dilated bowel loops.

Ultrasound will show choledocholithiasis, pneumobilia and an ectopic gall stone ${ }^{[29]}$. However USG may not always be useful due to anatomic alterations such as intestinal distension, collapse and presence of gas in the gall bladder.

Contrast enhanced computed tomography (CECT) is the investigation of choice. CECT will show

1. Small bowel obstruction

2. Ectopic gall stone (either rim calcified /total calcified)

3. Abnormal gall bladder with complete air collection, air fluid level or fluid accumulation.

4. The location of the fistula will also be delineated.

\section{The CECT findings in Bouveret's syndrome are}

1. Obstruction due to gastro duodenal mass

2. Pericholecystic inflammatory changes extending into the duodenum.

3. Gas in the gall bladder

4. Pneumobilia with a cholecysto-duodenal fistula

5. Filling defects corresponding to one or more gall stones

6. Thickened or contracted gall bladder.

CECT has an advantage of revealing oedema and ischaemia of the gut wall. The sensitivity of CECT is 93\%, specificity is $100 \%$ and accuracy is $99 \%{ }^{[30]}$.The only occasional drawback of CECT is that $15-25 \%$ of gall stones appear as isoattenuating in relation to bile and fluid ${ }^{[31]}$.

MRCP is indicated when the diagnosis is unclear on CECT ${ }^{[32,}$ 33]

It helps in differentiating gall stones from fluid and in identification of the fistula. As MRCP does not require oral contrast it is particularly useful in patients who have severe vomiting $[29,30]$.

Upper GI endoscopy may be contemplated in suspected cases of Bouveret's syndrome ${ }^{[20]}$. The gall stone is visualized in $69 \%$ of 
cases in the duodenal bulb, post bulbar duodenum or in the pylorus. Non-visualization of the stone is possible if the stone is deeply embedded within the mucosa. Diagnosis is suspect if the mass is hard, convex, smooth and non-friable.

Therefore CECT continues to be the investigation of choice as it enables early and definitive diagnosis.

\section{Treatment}

Surgery is the mainstay of treatment ${ }^{[25]}$.

Goals of surgical intervention in gall stone ileus are

1. Extraction of the obstructing gall stone

2. Closure of the biliary enteric fistula with removal of the gall bladder.

\section{The choice of procedures to accomplish the two goals are}

1. Enterolithotomy

2. Enterolithotomy with closure of the fistula with cholecystectomy. (one stage surgery)

3. Enterolithotomy followed by interval closure of fistula with cholecystectomy. (two staged procedure)

Since majority of patients presenting with gall stone ileus are advanced in age with many co morbidities the initial treatment comprises of aggressive rehydration, correction of fluid and electrolyte deficiencies and optimization of co morbidities. Once the general condition improves, surgery is contemplated ${ }^{[31,32,33]}$. Enterolithotomy is the fundamental procedure in gall stone ileus. $[33,34]$

At exploratory laparotomy the site of obstruction is located first. A longitudinal incision is then made on the antimesenteric border of bowel proximal to the site of impaction in order to ensure normal gut wall. The gall stone is gently manipulated towards the enterotomy and removed. The enterotomy is then closed in two layers transversely in order to avoid stricture and narrowing of the bowel. Making an incision on the oedematous bowel overlying the gall stone is avoided as far as possible due to issues with healing of the bowel wall. However in dire circumstances wherein a long segment of the proximal bowel is distended, an incision on the bowel wall overlying the gall stone is inevitable. If the bowel wall is thinned out, ischaemic or perforated then a resection anastomosis of the affected segment is essential ${ }^{[35]}$.

Impaction of the gall stone in the duodenum may be a challenging problem. For a gall stone impacted in the third part of the duodenum the stone should be manually moved to the small intestine and stone extraction done through the enterotomy site in the small bowel. In Bouveret's syndrome the gall stone is impacted at the duodenal bulb $[8,9,10]$. In such cases the lithotomy can be accomplished from the fistulous opening resection site. In rare circumstances part of the duodenal wall may have to be resected. An additional surgery involving an omental patch or small intestine serosal patch may be required to ensure safe healing of the duodenum.

If the site of impaction is the sigmoid colon then a single staged procedure is preferred ${ }^{[30,32]}$. The colon is invariably narrowed due to persistent inflammation as seen in diverticulitis. Hence resection of the narrowed segment is essential. Due to the high incidence of retrograde cholecystitis due to reverse flow of faeces from the fistula, closure of the fistula with cholecystectomy needs to be done at the same sitting as enterolithotomy. A proximal diverting colostomy is beneficial in protecting the anastomosis.

Closure of the biliary enteric fistula along with cholecystectomy is the next biggest challenge. Closure of fistula is essential as there are high chances of recurrence and the development of malignancy. The natural history of such fistulas is unpredictable for one to rely on the possibility of spontaneous natural closure of the fistula. The choice of a single staged versus two staged procedure continues to be a debatable issue. There is no scientifically proven consensus on this issue. Single staged procedure is associated with significant morbidity as well as high mortality as the patients are invariably aged with co morbidities. Hence they are unable to withstand the stress of surgery. However if the impaction is at the sigmoid colon a single staged procedure is preferable. However in other cases it is preferable to perform a two staged procedure which involves closure of the biliary enteric fistula with cholecystectomy at a later stage. This has two advantages. The initial enterolithotomy enables rescue from the surgical emergency and the time interval thereafter provides an opportunity to build up and prepare the patient for the second stage which is technically quite challenging.

The morbidity and mortality associated with a two staged procedure is considerably less as compared to a single stage procedure ${ }^{[34,35]}$.

With the advent of laparoscopy these procedures can be performed laparoscopically [35]. However due to lack of technical expertise and the unpredictable nature of the disease it is safe practice to adopt a two staged open approach as far as possible.

Endoscopic approaches have also been described. This approach is specifically applicable to gall stones impacted in the gastroduodenal and colonic region ${ }^{[34,35]}$. Fragmentation of the stone may be achieved by various ways, endoscopic mechanical lithotripsy, electrohydraulic lithotripsy, ESWL and laser lithotripsy ${ }^{[35]}$. There are anecdotal reports of successful endoscopic therapy for removal of the stone. Hence convincing evidence to support this option is lacking. Therefore this approach is not strongly advocated.

\section{Conclusion}

Gall stone ileus is a challenging complication of cholelithiasis. It affects old aged individuals with co-morbidities. High index of suspicion is necessary for a clinical diagnosis. CECT is diagnostic. Enterolithotomy with closure of the fistula and cholecystectomy as a two staged procedure is the safest option. Morbidity and mortality is significant in these patients.

\section{Conflict of interest: None}

\section{Funding: Nil}

Acknowledgements: I would like to thank Parth Vagholkar for his help in typesetting the manuscript.

\section{References}

3. Abou-Saif A, Al-Kawas FH. Complications of gallstone disease: Mirizzi syndrome, cholecystocholedochal fistula, and gallstone ileus. Am J Gastroenterol. 2002; 97:249-254.

4. Martin F. Intestinal obstruction due to gall-stones: with report of three successful cases. Ann Surg. 1912; 55:725743.

5. Clavien PA, Richon J, Burgan S, Rohner A. Gallstone ileus. Br J Surg, 1990; 77:737-742.

6. Reisner RM, Cohen JR. Gallstone ileus: a review of 1001 reported cases. Am Surg. 1994; 60:441-446.

7. Shi X, Vagholkar KR, Friess H, Uhl W, Buechler MW. Management of severe acute pancreatitis: Standards and 
Future Perspectives. Bombay Hospital Journal. 2001; 43:1627.

8. Halabi WJ, Kang CY, Ketana N, Lafaro KJ, Nguyen VQ, Stamos MJ et al. Surgery for gallstone ileus: a nationwide comparison of trends and outcomes. Ann Surg. 2014; 259:329-335.

9. Vagholkar K, Kripalani Y, Garima S, Vagholkar S. Common Bile Duct Stones: A Therapeutic Challenge. International Research Journal of Pharmacy and Medical Sciences (IRJPMS). 2019; 2(4):18-20.

10. Kasahara Y, Umemura H, Shiraha S, Kuyama T, Sakata K, Kubota H. Gallstone ileus. Review of 112 patients in the Japanese literature. Am J Surg. 1980; 140:437-440.

11. Vagholkar K. Acute cholecystitis: Severity assessment and management. International Journal of surgery science. 2020; 4(2):99-402.

DOI: https://doi.org/10.33545/surgery.2020.v4.i2e.433.

12. Yakan S, Engin O, Tekeli T, Calik B, Deneçli AG, Coker A et al. Gallstone ileus as an unexpected complication of cholelithiasis: diagnostic difficulties and treatment. Ulus Travma Acil Cerrahi Derg. 2010; 16:344-348.

13. Vagholkar K, Maurya I. Mirizzi’s Syndrome. The Internet Journal of Surgery. 2009, 25(1).

14. Vagholkar K, Pawanarkar A, Vagholkar S. Dropped gall stones: an entity in evolution. Int Surg J. 2016; 3:1048-50.

15. Ayantunde AA, Agrawal A. Gallstone ileus: diagnosis and management. World J Surg. 2007; 31:1292-1297.

16. Masannat Y, Masannat Y, Shatnawei A. Gallstone ileus: a review. Mt Sinai J Med. 2006; 73:1132-1134.

17. Vagholkar K. Acute cholangitis: Diagnosis and management. International journal of surgery Science. 2020; 4(2):601-604. DOI: https://doi.org/10.33545/surgery.2020.v4.i2g.447.

18. Vagholkar K, Pawanarkar A, Vagholkar S, Pathan S, Desai R. Post cholecystectomy pancreatitis: a misleading entity. Int Surg J. 2016; 3:941-3.

19. Chavalitdhamrong D, Donepudi S, Pu L, Draganov PV. Uncommon and rarely reported adverse events of endoscopic retrograde cholangiopancreatography. Dig Endosc. 2014; 26:15-22.

20. Yamauchi Y, Wakui N, Asai Y, Dan N, Takeda Y, Ueki N et al. Gallstone Ileus following Endoscopic Stone Extraction. Case Rep Gastrointest Med. 2014, 271571.

21. Zehetner J, Shamiyeh A, Wayand W. Lost gallstones in laparoscopic cholecystectomy: all possible complications. Am J Surg. 2007; 193:73-78.

22. Koulaouzidis A, Moschos J. Bouveret's syndrome. Narrative review. Ann Hepatol. 2007; 6: 89-91.

23. Cappell MS, Davis M. Characterization of Bouveret's syndrome: a comprehensive review of 128 cases. Am J Gastroenterol. 2006; 101:2139-2146.

24. Rigler LG, Borman CN, Noble JF. Gallstone obstruction: pathogenesis and roentgen manifestations. JAMA. 1941; 117:1753-1759.

25. Balthazar EJ, Schechter LS. Air in gallbladder: a frequent finding in gallstone ileus. AJR Am J Roentgenol. 1978; 131:219-222.

26. Ripollés T, Miguel-Dasit A, Errando J, Morote V, GómezAbril SA, Richart $\mathrm{J}$ et al. Gallstone ileus: increased diagnostic sensitivity by combining plain film and ultrasound. Abdom Imaging. 2001; 26:401-405.

27. Yu CY, Lin CC, Shyu RY, Hsieh CB, Wu HS, Tyan YS et al. Value of CT in the diagnosis and management of gallstone ileus. World J Gastroenterol. 2005; 11:2142-2147.
28. Pickhardt PJ, Friedland JA, Hruza DS, Fisher AJ. Case report. CT, MR Cholangiopancreatography, and endoscopy findings in Bouveret's syndrome. AJR Am J Roentgenol. 2003; 180:1033-1035.

29. Ravikumar R, Williams JG. The operative management of gallstone ileus. Ann R Coll Surg Engl 2010; 92: 279-281.

30. Tan YM, Wong WK, Ooi LL. A comparison of two surgical strategies for the emergency treatment of gallstone ileus. Singapore Med J. 2004; 45:69-72.

31. Riaz N, Khan MR, Tayeb M. Gallstone ileus: retrospective review of a single centre's experience using two surgical procedures. Singapore Med J. 2008; 49:624-626.

32. Nuño-Guzmán CM, Arróniz-Jáuregui J, Moreno-Pérez PA, Chávez-Solís EA, Esparza-Arias N, Hernández-González CI et al. Gallstone ileus: One-stage surgery in a patient with intermittent obstruction. World J Gastrointest Surg. 2010; 2:172-176.

33. Franklin ME Jr, Dorman JP, Schuessler WW. Laparoscopic treatment of gallstone ileus: a case report and review of the literature. J Laparoendosc Surg. 1994; 4:265-272.

34. Bedogni G, Contini S, Meinero M, Pedrazzoli C, Piccinini GC. Pyloroduodenal obstruction due to a biliary stone (Bouveret's syndrome) managed by endoscopic extraction. Gastrointest Endosc. 1985; 31:36-38.

35. Roberts SR, Chang C, Chapman T, Koontz PG, Early GL. Colonoscopic removal of a gallstone obstructing the sigmoid colon. J Tenn Med Assoc. 1990; 83:18-19.

36. Moriai T, Hasegawa T, Fuzita M, Kimura A, Tani T, Makino I et al. Successful removal of massive intragastric gallstones by endoscopic electrohydraulic lithotripsy and mechanical lithotripsy. Am J Gastroenterol. 1991; 86:627629.

37. Gemmel C, Weickert U, Eickhoff A, Schilling D, Riemann JF. Successful treatment of gallstone ileus (Bouveret's syndrome) by using extracorporal shock wave lithotripsy and argon plasma coagulation. Gastrointest Endosc. 2007; 65:173-175. 